\title{
Fashion Designer Brand Operation Strategy Analysis Based on Internet
}

\author{
Mingyuan Zhang \\ Business Institute \\ Beijing Institute of Fashion Technology \\ Beijing, China \\ bjzhangmingyuan@163.com
}

\author{
Shui Jin* Corresponding Author \\ Fashion Communication Institute \\ Beijing Institute of Fashion Technology \\ Beijing, China \\ jinshui@126.com
}

\begin{abstract}
With the advent of consumer upgrading, consumer shopping ability is increasing, and more and more consumers have a growing demand for clothing. In this paper, we explore the management of clothing designer's brand under the Internet environment, combined with the current situation of Internet environment, and provide operational strategies for apparel designer's brand internet to help brand growth.
\end{abstract}

Keywords—component; formatting; style; styling; insert

\section{SWOT OF FASHION DESIGNER BRAND}

Fashion designer brand should be independent design research and development, production and sales of small type of clothing brand. In the business model, these brands are more particular about the unique design than the commercial brands, and the consumer groups have less audience. The crowd positioning looks relatively small, the main reason is that the cut is a much fractionized market. But with the development of the brand, the individual brand also bound to the mass market, of course, more designers also continue to adhere to the brand niche.

\section{A. Strengths}

Many designers, as a star, have a certain appeal and influence in the fashion and other surrounding areas. To make up a circle of designers and fans, they use their own views on fashion and wear to carry out the culture and product of their brands.

Each independent fashion designer brand is dominated by the "original" design style. Designers enjoy full autonomy to meet the needs of diversified personalities.

When it comes to service, the upgrading of consumption also is bound to promote service upgrade. That is to say, when consumers have higher purchasing power, there will be more related areas of demand. Fashion designer brand can take advantage of the brand's own design ability to carry out services such as designed and customized services and clothing collocation. High value-added services will make designer brands different from other commercial brands, and bring new opportunities for designer brands.

\section{B. Weaknesses}

The more well-known fashion designer brands such as CHI ZHANG, YE'S, Xander Zhou, Ji Cheng, quarterly product 30-
40, mostly from the show moved directly to online sales, and sales price limit occasion restrictions, product design style, the other popular consumer is difficult to accept. Of course, there are too many young fashion designer brands that tend to be quick and quick, easily confused by the media's propaganda and their product level is unstable every season.

For most fashion designer brands, let alone the flexible supply chain, even the ability of the next order is a problem. The factory is not willing to answer the bill because of the small amount. Therefore, there is no healthy supply chain integration capability, which will lead to the increase of cost and price, which is also the core reason that hinders the development of some fashion designer brands.

Fashion designers are not good at retail, and brands are generally lack of marketing teams to promote brands, and develop targeted marketing strategies and channels integration. Besides, brands cannot afford to spend a lot of money in the promotion process, and there is no sustainable business mode, which will lead to the fear of brand designers.

Many designer brands are worried about the shortage of money in the early days of the establishment. From the shop, decoration, personnel costs, brand publicity, production and so on, designer brands need to spend money. Often, many designers are in a very difficult position. After maintaining the 1-2 seasons, they will choose to quit the market. Of course, there are still few designer brands, but they will not expect too much.

\section{Opportunities}

Although most of the fashion designer brands from the electric business come from Taobao.com. But the growth path of these designer brands will undoubtedly make other electric business platforms see opportunities and breakthroughs, and good designer brands and products will not be buried. The potential of the domestic electricity supplier market is huge. Taobao.com, JD.com, vip.com and ShangPin.com have built up a mature designer to show the promotion channel. At the same time, using PC terminal, mobile terminal and other multichannel resources to promote clothing designer brand, Support the new brand of independent designer. Each business platform, also with the advantage of faster and better transmission speed and breadth of electricity providers than traditional means, enables more people, consumers both at home and abroad, to quickly understand these designers' quality products. 
Different from the offline entity buyer store, the ecommerce platform has more kinds of marketing methods, such as public financing, pre sale and content marketing. These marketing models have accelerated the communication between the designer and the consumer. It is also convenient for designers to understand the market at the first time and respond quickly to the design of the later product design and the production plan. Greatly saving time and control cost, reducing stock pressure.

\section{Threats}

The speed and breadth of the rapid spread of e-commerce platform is a double-edged sword. Besides helping brand promotion and publicity, it also caused a lot of plagiarism. At present, China's intellectual property system is not perfect and its supervision is not perfect. Meanwhile, designers' awareness of rights protection is relatively weak, making designer brand and commercial brand in a vicious competition environment, which is not beneficial to the development of any brand and apparel industry.

The price of the clothing designer is generally high, and in the environment of the Internet, the consumer's purchase has not been fully guided. At the same time, online shopping, consumers only rely on the introduction of pictures, videos and texts; it is difficult to ensure user satisfaction, which is also very easy to cause an increase in the return of goods.

The time of brand emergence of Chinese fashion designers is relatively short. Many brands still have no initiative in supply chain and operation, so it is hard to get better economic and brand benefits. And international marketing capabilities and marketing channels are still very limited, so it will take some time to go to the international fashion stage.

\section{THE COUNTERMEASURES OF FASHION DESIGNER BRAND INTERNET OPERATION}

To be a designer brand, or to be a "good" designer brand. Although the difference of a word, but the difference is more reflected in the attitude of the brand manager. Then combined with the current situation in the Internet environment, clothing designer brands should be more beneficial and avoid harm.

Then, how should clothing designer brand face those problems in the Internet brand management? This article will focus on the analysis of designer brand supply chain management, identifying sales platform, brand image building, product, price and operation mode.

\section{A. Supply chain support}

Fabric and excipient resources directly affect designers' creative expression for design works. Production and processing decide the key to the product's stock and inventory after listing. Therefore, the integration of fabric and accessories resources and supply chain is a key factor in the brand. [1]

SHANG JIE (generation operating company of the Shanghai Textile Association) has been working to provide solutions for the lack of ability to integrate the designers in this area. Shang Street will pick out a good product in the designer's products every season. The use of its own supply chain for product production, thus also make the brand of designer labels tend to be reasonable, and promote the benign development of the brand.

\section{B. Finding the positioning of the platform}

At present, a large number of e-commerce platforms are taking up designer market resources. Such platforms as Taobao.com and JD.com have relatively high threshold. They have higher requirements for designers in product market reaction speed, supply, brand qualification and operation ability.

Subsequently, offline buyer shops, showroom, such as SHIJIE, DHUB and so on, are also providing designers with online and offline display space to solve their operational problems.

The domestic market appeared a lot of B2B platform, the platform is mainly concentrated in Jiangsu and Zhejiang and Guangdong area, there are two main modes of cooperation, one is the integration of clothing designer resources front and styles; the other is the integration of a large number of back-end plant resources, to both docking costume designers and factory needs.

In the 16 winter, the famous men's wear designer Xander Zhou and the men's wear brand HLA cross-border cooperation, launched the "Xander Zhou+HLA", the market repercussion is excellent, in the JD\&HLA brand days, goods on the shelves for 7 minutes, the main push has been sold out. Thus, realize the win-win of designer and brand.

Therefore, every garment designer and brand needs to find the corresponding platform according to its own situation, to attract the popularity and to expand the brand influence.

\section{Brand strategy}

The establishment of an independent design brand, its name, LOGO, and the interpretation of the concept of each season have a crucial and subtle impact on the brand. [2] In addition to relying on the unique design itself, such as how to brand story, advertising creative further into the product value, and through multiple channels for brand promotion, in order to "talk" brand, enhance consumer awareness of the brand, brand is the ultimate influence, and many independent designers were bound.

Although there is no policy specification for clothing designer at home, but independent designer brand still needs to take a professional attitude and attitude to do copyright registration for design and prove its priority in power. Ji Cheng, the designer said, hopes to express an attitude by himself: it is time to pay attention to intellectual property. The more original designers who insist on the voice and attitude of rights, the wider the road will be.

\section{Product strategy}

Most of the young clothing designer brands can see more or less the shadow of other brands in their series of works, mainly because their brand positioning and style have not yet formed. For these brands, we should pay more attention to constantly developing unique and distinctive products, developing ideas, shaping brand image and abandoning the concept of "niche", or 
discard the concept of commercialization. Down to earth, loyal service to the brand target consumer is the king.

\section{E. Price strategy}

For fashion designer brands, a big pain point is the "pricing system". Clothing products belong to the category of high demand price elasticity, and the consumers' sensitivity to the price of clothing and clothing products is generally high.

Compared with the internationally known clothing designers and brands, such as Ralph Lauren, Vera Wang and so on, Chinese clothing designers haven't reached a certain height, but the price tag is almost the same with those brands, and most consumers are unbearable.

In the competition of designer brand, price is not the main competitive means, but it plays a key role in consumer's concern about brand, designer, product and transformation. [3]

\section{F. Set up a stable and efficient team}

Most fashion designer brands are made up of studio or small team. They only include designers, design assistants, print masters and sample workers. No staffing has been set up in the procurement and marketing posts. These designer brands will not set up a related operation team for e-commerce channels alone. But to establish a clear division of labor, stable and efficient operation mechanism, to ensure the stable development of the brand is still very necessary.

\section{G. Operation model}

The Internet ecommerce platform also provides large data and marketing support for designer brands. For example, it is convenient for designers to test water before the product is listed on a large scale to reduce the risk of inventory cost and so on.

Brands do a good job in the management of outreach, such as media promotion and publicity, celebrities wearing exposure, film and TV plays and so on.

This year the newly established Designer: JUN by YO, created by Mr. Hu Jun and actor stylish designer and fashion industry investor Ms. Wang Yiou's men's designer brand. A month before the first show in September 6th, the JUN by YO brand participated in the JD.com Crowd-funding activities to offer awards to consumers in the event and the new dress. During the 20 day period, the total amount was about 100000.

SOIREE, The Internet designer luxury brand, adopts the innovative operation mode on WeChat platform, through the way of word of mouth marketing, since the vast majorities of consumers are familiar with their brand, and are transformed and collected because of its marketing mode.

These are favorable for the Internet brand; clothing designer brands do better operational model cases. As long as each brand, find suitable for their way, will be a lasting and benign development.

\section{CONCLUSION}

More and more independent fashion designers begin to embrace the Internet, devote themselves to brand promotion and product sales. At present, nearly 100 designer brands have entered JD.com. Through contacting with designer brand and designer, the author combines the operation experience of Internet brand, and analyzes the operation strategy of clothing designer brand under the Internet environment. The designer brand is a very small market, and how to grow better in the Internet brand needs constant attempt.

China's fashion industry needs continuous progress and growing. And the designer is part of the whole Chinese fashion industry chain to serve the development of the whole Chinese fashion industry. [4]The consumer is the only factor in determining the market. The designer can finally make the consumer choose to be successful. I believe that more brands of fashion designers can be better developed.

\section{REFERENCES}

[1] Junpeng,Xing, “On the development of independent designer brand," Oriental Enterprise Culture, 2015(13).

[2] Mingli, "5 major crux and Countermeasures in the early stage of designer brand creation,” in press.

[3] Yue Yuan, "Research on designer brand strategy[D]," Tianjin Polytechnic University, 2015.

[4] Beijing Business Today, "The future of Chinese designers: to know the consumer to have a market,” April 2014, in press. 